\title{
Swedish high-school pupils' attitudes towards drugs in relation to drug usage, impulsiveness and other risk factors
}

Background: Illicit drug use influences people's lives and elicits unwanted behaviour. Current research shows that there is an increase in young people's drug use in Sweden. The aim was to investigate Swedish high-school pupils' attitudes, impulsiveness and gender differences linked to drug use. Risk and protective factors relative to drug use were also a focus of interest.

Method: High school pupils $(n=146)$ aged 17- 21 years, responded to the Adolescent Health and Development Inventory, Barratt Impulsiveness Scale and Knowledge, and the Attitudes and Beliefs. Direct logistic, multiple regression analyses, and Multivariate Analysis of Variance were used to analyze the data.

Results: Positive Attitudes towards drugs were predicted by risk factors (odds ratio $=37.31$ ) and gender (odds ratio $=.32$ ). Risk factors (odds ratio $=46.89$ ), positive attitudes towards drugs (odds ratio $=4.63$ ), and impulsiveness (odds ratio $=1.11$ ) predicted drug usage. Risk factors dimensions Family, Friends and Individual Characteristic were positively related to impulsiveness among drug users. Moreover, although boys reported using drugs to a greater extent, girls expressed more positive attitude towards drugs and even reported more impulsiveness than boys.

Conclusion: This study reinforces the notion that research ought to focus on gender differences relative to pro-drug attitudes along with testing for differences in the predictors of girls' and boys' delinquency and impulsiveness. Positive attitudes towards drugs among adolescents seem to be part of a vicious circle including risk factors, such as friendly drug environments (e.g., friends who use drugs) and unsupportive family environments, individual characteristics, and impulsiveness. 
${ }^{1}$ Network for Empowerment and Well-Being, Sweden of Gothenburg, Sweden

${ }^{3}$ Department of Psychology, University of Gothenburg, Sweden ${ }^{4}$ Department of Psychology, University of Turku, Finland ${ }^{5}$ Department of Psychology. Stockholm University. Stockholm. Sweden

6 *Correspondence: F. Mousavi. E-mail: fariba_mousavi@yahoo.se or to D. Garcia, CELAM, 7 University of Gothenburg, Wallinsgatan 8, SE 43141 Mölndal, Sweden. E-mail:

8 danilo.garcia@neuro.gu.se; danilo.garcia@euromail.se 
9 A drug abuser may be defined as an individual who has relinquished control over his/her

10 life to psychoactive substances (Fraser \& Moore, 2008). This condition produces altered

11 neurological functions, and changed perceptions, moods, consciousness and energy levels (King,

12 2008). The user turns into an 'abuser' when a drug impacts his/her normal functioning and well-

13 being (Johnston \& O'Malley, 1986). The label 'abuser' covers the inappropriate use of any

14 substance, especially those that alter consciousness (e.g., alcohol, cocaine methamphetamines)

15 and generate significant distress and function impairment (Medical Dictionary, 2013). Drug

16 abuse, although disapproved by most societies, may involve the illegal use of drugs for

17 recreational purposes or for the relief of medical problems without a health care practitioner's

18 recommendation (Merck Manual, 2009). Drugs have been used universally in all cultures and all

19 social classes, for example alcohol was a common intoxicant in ancient Greece, in South

20 America, indians have chewed the leaves of the raw material that make up cocaine production

21 (Goldberg, 1993), and opium has been used as both an intoxicant and medicine in many cultures,

22 especially China (Ramström, 1983). Several studies have contributed to understanding of the role

23 of drugs in different cultural contexts, such as drinking contributes to British identity among

24 Australian skinheads (Moore, 1994) and the pub culture can be understood as an expression of

25 the working class and 'masculinity' (Sulkunen et al, 1997). The global annual prevalence of illicit

26 drug users was estimated to be 3.30-6.10\% in people aged 15-64 years in 2009 (United Nation

27 Office on Drugs and Crime, 2011). Cannabis is the most frequently used drug with a projected

28 global annual prevalence rate of $2.80-4.50 \%, 10.70 \%$ in North America and $6.80 \%$ in Europe

29 (European Monitoring Centre for Drugs and Drug Addiction, 2010).

30 In this context, according to alcohol sales statistics, beer intake is dominant in most of

31 Europe, including Scandinavia, whereas wine is consumed more often in Southern Europe. In

32 Sweden for instance, the average consumption for an adult is assessed to be nine !!! liters of

33 alcohol per year (Anderson et al., 2012), while 2.30\% of 16-84 year-old individuals use cannabis 
34 for recreational purposes (National Institute of Public Health [NIPH] 2011). Among adolescents,

$3520 \%$ of Swedish boys and $15 \%$ of Swedish girls have used drugs at one time or another. In upper

36 secondary grade school, beer is dominant among Swedish boys (48\%), followed by spirits (25\%),

37 and mixed drinks (13\%). Among Swedish girls, mixed drinks (32\%) and spirits (27\%) are the

38 most consumed forms of alcohol (Henriksson \& Leifman, 2012). According to the NIPH

39 (2009/10), Swedish school children's drug usage has increased slightly in recent years. Drug

40 availability is considerably enhanced and is linked to positive attitudes to experiment with

41 alcohol and other drugs. While the proportion of drug usage seems to have levelled off among

42 girls, it has risen from $16-17 \%$ in $2004-2008$ to $21 \%$ in 2010 among boys (Henriksson, \&

43 Leifman, 2012). For instance, Taylor Nelson Sofres Sifo (TNS Sifo; 2012) surveyed all high-

44 school students in Stockholm, including the high school targeted in the present study. The TNS

45 Sifo Gallup survey showed that $27 \%$ of the boys and $15 \%$ of the girls had tried drugs during the

46 year 2012. The high school included in the present study had a drug-user increase from $16 \%$ to

$4721 \%$. This observation implies that the number of adolescents expressing a more positive attitude

48 towards drugs may have increased.

49 Attitudes towards drugs

50 An attitude is defined as a psychological tendency expressed by an approval or a

51 disapproval of a person or thing. In particular, attitudes facilitate an individual's judgment for

52 goal achievements, determination of consequences or conveyance of attitudes to other individuals

53 and an individual seeks an environment with attitudes consistent with his own (Augustsson,

54 2005). Changes in an attitude may be perceived as an attempt to balance the social environment

55 (Helkama, Myllyniemi \& Liebkind, 2004), for example, peer conformity (Aronson, Wilson, \&

56 Akert, 2005)". Nevertheless, Rytterbro (2006) and Rödner and colleagues (2007) revealed an

57 ongoing general liberalization of attitudes towards drugs among young people. Drug users seem

58 to attribute positive effects to illicit drugs to 'play down' their negative effects - for example, by 
believing that cannabis is less harmful than other drugs and that cannabis use may not be perhaps

60 as harmful as alcohol.

61 Parental knowledge concerning teenage activity and residence are also important

62 predictors of drug abuse. However, it is not the parents' active questioning or monitoring per se,

63 but the teenager's own narrative that constitutes an important basis for our understanding on drug

64 usage (Kakihara et al., 2010; Keijsers et al., 2010; Kerr, Stattin, \& Burk, 2010). The likelihood

65 that a young person develops into a drug user and abuser is increased through peer pressure, at an

66 age when familiarity with negative abuse effects is limited. Furthermore, young people have

67 difficulties in telling if friends are using drugs or not (Andersson, 1991). Moreover, compared to

68 girls, boys are exposed earlier to intoxicating substances (Van Etten \& Anthony, 2001) and have a

69 greater liability for lifetime prevalence of exposure to illicit substances (Aarnoudse, Dieleman, \&

70 Stricker, 2007; Gray, 2007). It appears that the pattern in female drug usage is related to some

71 extent to intimate relationships, while the male model links to independence and freedom

72 (Trulsson, 2006).

73 Risk factors and protective aspects relative to drug abuse

74 Risk factors for drug use comprise uninvolved parents, peer pressure, hostility towards the

75 child and harsh punishments, poor school or academic achievements, low socioeconomic status

76 and availability of drugs (Hawkins, Catalano, \& Miller, 1992; Merline et al., 2004; Schuster et

77 al., 2001). Additionally, attention deficit and hyperactivity disorder, personality traits such as lack

78 of empathy (i.e., low communal values or cooperativeness), impulsiveness (i.e., low agency or

79 self-directedness), non-attendance in local environmental issues (i.e., low self-transcendence),

80 fearlessness, sensation-seeking and lack of emotion regulation constitute individual-specific risk

81 factors for drug abuse (Andershed \& Andershed, 2005; Loeber \& Farrington, 1998). Importantly,

82 a personality characteristic such as impulsiveness is a major contributor to drug consumption and

83 having a positive attitude towards drugs, which in turn also increases risky behaviour (Hawkins et 
84 al., 1992). At the personal level, a human being's level of vulnerability constitutes an individual-

85 specific risk factor, which puts the person at danger for developing antisocial and aggressive

86 behavior (Gross, 2007). Poor emotional regulation leads to, instead of using cognitive strategies,

87 the use of physical violence to retaliate, especially among males (Kåver \& Nilsonne, 2002).”

88 Women, for instance, are known to use on average less drugs than men (Van Etten \& Anthony,

89 2001). Kloos and colleagues (2009), for instance, suggested social and cultural norms might

90 explain gender differences in drug abuse. Traditionally, females fear to lose control in a social

91 context; consequently fewer women succumb to drug misuse whereas drug consumption may

92 serve a purpose in regulating emotions, especially anger and impulsiveness (Kloos et al., 2009).

93 Conversely, health-related behaviour in adolescence is influenced by immediate social and

94 environmental factors, such as closeness, cohesion and care of family, which lower the risk for

95 substance abuse (Duncan, Duncan, \& Strycker, 2003; Hill et al., 2005; Pires \& Jenkins, 2007;

96 Sale et al., 2005). Stattin and Kerr (2000) found that parents with rules for their teens decreased

97 the risks for antisocial behaviour (see also Kakihara et al., 2010). On the other hand, parents who

98 communicate with their teens convey a better understanding by supporting and guiding them.

99 Teenagers who have a good and respectful relationship with their parents are more likely to

100 imitate their parents' attitudes, which may affect their use of alcohol and drugs (Keijsers et al.,

101 2010; McNeely \& Barber, 2010). Close relationships promote transparency and reduce the risk

102 that the teenager would engage in antisocial behaviour (Vieno et al., 2009).

\section{The present study}

104 The purpose of the present study was to investigate high-school pupils' attitudes towards 105 drugs, impulsiveness and other risk factors relative to their use of drugs for non-medical reasons. 
106 Due to the widespread and complex aspect of the problem, only three specific research questions

107 were examined in the present analysis:

108 Which factors contribute to high-school students' positive attitude towards drug

$109 \quad$ usage?

$110 \quad$ 2. Which factors contribute to high-school students' drug usage?

$111 \quad$ Which factors contribute to drug users' impulsiveness?

112

Method

113 Ethical statement

114 After consulting with the university's Ethical Review Board (University of Gothenburg) 115 and according to law (2003: 460, §2) concerning the ethical research involving humans we 116 arrived to the conclusion that the design of the present study (e.g., all participants' data were 117 anonymous and will not be used for commercial or other non-scientific purposes) required only 118 informed consent from participants and a signed consent from the principal of the participating 119 high school.

\section{Participants and procedure}

121 Altogether 15 high-schools' principals in Stockholm, Sweden, were approached until a

122 principal for a high school agreed to participate in the present study. The staff of the schools that 123 declined to participate did so due lack of time or found the drug issue to be irrelevant to students' 124 curriculum. At the participating high school, a total of 160 questionnaires were handed out to the 125 pupils aged 17- 21. In this part of Sweden (the Stockholm region), drug issues are a known 126 problem (CAN, 2012; NIPH, 2009/10 \& TNS Sifo, 2012). Fourteen (9\%) pupils refused to 127 participate or did not complete the forms accurately and were thus excluded from the study. 128 Accordingly, the sample comprised 146 (91\%) pupils who attended a 3-year Natural Science or 129 Social Science program. The boys $(47.30 \%)$ were on average $18.20(S D=0.65)$ and the girls 
$130(51.40 \%)$ were on average $18.03(S D=0.57)$ years. Their parents' had educational levels ranging

131 from: no education (1.40\%), high school (8.90\%), upper secondary school (17.10\%), vocational

132 education $(1.40 \%)$ to university $(52.60 \%)$. Thus, suggesting that a majority of the pupils had

133 parents with higher education. A total of $15.10 \%$, however, did not respond to this question. The

134 majority of the participants were Swedish $(n=143), 1$ was from Russia, 1 was from Georgia and

1351 was from Iran. The majority of the pupils $(88.40 \%)$ indicated the big city as their place of

136 upbringing, $10.30 \%$ indicated a small city and $1.40 \%$ did not answer this question

137 The survey was conducted at the school during an English lecture at high-school C level.

138 The researcher delivered the questionnaire to the school principal. The questionnaire (127

139 questions) comprised measures of impulsiveness, attitudes towards drugs, protective and risk

140 factors for students' drug use, and some background variables. Furthermore, before handing out

141 the questionnaires the researcher received a written assent letter signed by the principal. Then in 142 turn, the principal informed every C-level English teacher that they would ensure that the 143 students participated in the survey and completed the questionnaires during the English lesson. 144 The pupils were informed that the study was anonymous, voluntary, required a duration of 45 $145( \pm 5)$ minutes, and that they were free to discontinue the completion of the form whenever they 146 wanted without any justification. After completion, pupils were instructed to seal the survey in an 147 envelope that was handed to the teacher. Data collection took place from mid-November 2012 to 148 January 2013.

149 Statistical treatment

150 By means of linear and logistic regression analyses as well as Multivariate Analysis of 151 Variance (MANOVA) students' use or non-use of drugs and attitudes towards drugs provided the 152 dependent variable, while gender, age, level of impulsiveness, risk and protective factors 153 constituted the independent variables. To avoid a too small sample, 146 questionnaires (x 127 154 questions) were collected which well exceeded the requirement of at least 15 individuals per 
155 predictor in regression analysis (Pallant, 2001). This sample size also reduced the occurrence of

156 false significances in MANOVA.

\section{Measures}

158 Participants' background. The background instrument comprised 5 items about socio-

159 demographic data including the respondent's age, gender, home country, place of upbringing and 160 level of parent's education.

161 Drug use. This part of the form contained a total of 4 items. Participants were asked to 162 indicate if they have used drugs for non- medical reason (Yes, No) the type of drugs the 163 respondent had used, his/her age at the first use of various drugs and the frequency of drug use. Attitudes towards drugs. The Knowledge, Attitudes and Beliefs inventory (Bryan et al., 2000), was modified for this study and consisted of 21 items in which participants answer the

166 questions regarding their attitudes to drug use (e.g.. "Our society is too tolerant towards drug users", "Occasional use of cannabis is not really dangerous", "It is normal that young people will try drugs at least once”, "Reports about the extent of drug usage amongst young people are exaggerated by the media”). The items were answered using a 7-point Likert scale (1= Disagree strongly. 2= Don't agree. 3 = Agree strongly. $4=$ Agree moderately. $5=$ Agree slightly. $6=$ Don't

171 know. 7 = I don't care). For the purpose of the present study, and as recommended by Bryan and 172 colleagues, the response options were collapsed into two categories (Agree and Disagree). In

173 other words, categorizing participants in those who had a positive attitude towards drugs and 174 those who did not had a positive attitude towards drugs. Nevertheless, using the whole scale the 175 Cronbach's alpha coefficient for this measure was .72 Risk and protective factors. The Adolescent Health and Development (Jessor, Turbin, \&

177 Costa, 1998b) and the Communities That Care (Hawkins \& Catalano, 1992) questionnaires assess 178 a variety of behaviours as well as a range of risk and protective factors in different domains (3-4 179 items for each domain) using a 4-point Likert scale $(1=$ Almost always, $4=$ Almost never $)$. The 
180 domains include Family (Risk factor item example: "People in my family often insult or yell at

181 each other"; Protective factor item example: "My parents give me lots of chances to do fun things

182 with them"), Community (Risk factor item example: "I would like to get out of my

183 neighbourhood"; Protective factor item example: "There are people in my neighborhood who

184 encourage me to do my best"), Friends (Risk factor item example: "How wrong do you think it is

185 for someone your age to smoke marijuana?"; Protective factor item example: "If you were doing

186 something that is bad for your health, would your friends try to get you to stop?"), and Individual

187 Characteristics (Risk factor item example: "I do the opposite of what people tell me, just to get

188 them mad"; Protective factor item example: "It is important to be honest with your parents, even

189 if they become upset or you get punished"). We also constructed a total score for measuring risk

190 and protective factors as a whole, by simply adding all items in the risk and protective domain.

191 The reliability by Cronbach's alpha for risk factors with 32 items was .83 and for protective 192 factors with 14 items .84.

193 Impulsiveness. The Barratt Impulsiveness Scale, (BIS-11; Patton, Stanford, \& Barratt, 194 1995) contains a total of 30 items, each of which is answered on a 4-point Likert scale $(1=$

195 Rarely/never. 4 = Almost always/always). The level of impulsiveness is calculated by summing

196 up the scores for each item, the higher score, the more impulsiveness. The Cronbach's alpha for 19729 items, after factor analysis, was .84.

\section{Results}

Respondent characteristics as well as the means and standard deviations for different measurements performed are provided in the supplemental material (Table S1). An explorative analysis, before testing the specific research questions, showed that boys used more drugs (41\%

202 of the boys compared to $21 \%$ of the girls). A total of $4.80 \%$ of the pupils who indicated using 203 drugs reported using alcohol, $5.50 \%$ of these pupils reported using cannabis, $4.80 \%$ marijuana 204 and $16.40 \%$ did not answer this specific question. The frequency of drug usage was $0.70 \%$ 
205 weekly, $0.70 \%$ monthly, $3.40 \%$ only once, $0.70 \%$ every two months, $0.70 \%$ every three weeks,

$2061.40 \%$ just three times, $0.70 \%$ sometimes not very often, $1.40 \%$ only two times, and $21.90 \%$ did 207 not answer. The distribution of pupils reported when they started using drugs was as follows:

$2082.70 \%$ by age $13,7.50 \%$ by age $15,8.90 \%$ by age $16,8.20 \%$ by age $17,2.70 \%$ by age 18 , and

$209 \quad 1.40 \%$ did not answer the question.

210 Chi-square for independence testing was used to explore the relationship between gender 211 and positive attitudes towards drugs and gender and drugs usage. A Chi-square test for 212 independence (with Yates Continuity Correction) indicated significant association between 213 gender and positive attitudes towards drugs, $\mathrm{X}^{2}(1, n=118)=10.89, p=.001$, phi $=.32$. All 214 expected cell sizes were greater than 5 (in this case, greater than 23.67). Even a Chi-square test 215 for independence (with Yates Continuity Correction) indicated significant association between 216 gender and drugs usage, $\mathrm{X}^{2}(1, \mathrm{n}=144)=5.40, \mathrm{p}=.02$, phi $=.21$. Also here, all expected cell 217 sizes were greater than 5 (in this case, greater than 21.08). The phi coefficients in both analys (.32 218 for positive attitudes towards drugs and .21 for drugs usage) can be considered a medium and 219 small effect size, respectively, using Cohen's (1988) criteria.

An independent-samples t-test was conducted to compare the total sum of risk factors 221 scores for males and females. There was a significant difference $(t(121)=1.95, p=.053$, two222 tailed $)$ in scores for males $(M=67.61, S D=10.77)$ and females $(M=63.95, S D=9.97)$. The 223 magnitude of the differences in the means was small (eta squared $=.03$ ). For complementary 224 analyses, the numbers of included items as well as the value of Cronbach's alpha for each 225 instrument, see Table S1.

\section{Attitude towards drugs}

Direct logistic regression was performed to assess the impact of factors on the likelihood

228 that respondents would report that they were likely to express a positive attitude towards drugs.

229 The model contained five factors or independent variables (gender, age, impulsiveness, total sum 
230 of risk factors and total sum of protective factors). The full model containing all predictors was

231 statistically significant $\left(\chi^{2}(5, N=117)=30.27 p<.0001\right)$. That is, the model distinguished

232 between respondents who were categorized as having a positive attitude towards drugs from

233 those who were categorized as not having a positive attitude towards drugs. The model as a

234 whole explained between 22.80\% (Cox and Snell R square) and 30.70\% (Nagelkerke R squared)

235 of the variance in attitudes towards drugs, and classified correctly $76.10 \%$ of these cases. As

236 shown in Table 1, two of the independent variables made a unique statistically significant

237 contribution to the model, gender and the total sum of risk factors. The strongest predictor of

238 reporting positive attitudes towards drugs was the total sum of risk factors with an odds ratio of

239 37.31. This indicated that respondents who live in more risk factor-prone environments

240 (including Family, Community, Friends, and Individual Characteristics) were over 37 times more

241 likely to report a positive attitude towards drugs than those who did not live under such risk

242 factors, controlling for all other variables in the model.

Table 1 should be here

244 Drug usage

245 Direct logistic regression was performed to assess the impact of factors on the likelihood

246 that the respondents would report that they had used drugs. The model contained 6 independent

247 variables (age, gender, totals sums of risk factors, total sum of protective factors, impulsiveness,

248 and attitudes towards drugs). The model containing all predictors was significant $\left(X^{2}(6, N=117)\right.$

$249=49.41, p=0.0001$ ), thereby indicating that the model was able to distinguish between

250 respondents who reported using drugs and those who reported not using drugs. The model as a

251 whole explained between 34.4\% (Cox and Snell R square) and 48.1\% (Nagelkerke R squared) of

252 the variance in drug use and correctly classified $84.6 \%$ of the cases. As shown in Table 2 , three of

253 the independents variables made an unique contribution to the model (totals sums of risk factors,

254 impulsiveness and attitudes towards drugs). The strongest predictor of drug usage was risk 
255 factors (including Family, Community, Friends, and Individual Characteristics), recording an 256 odds ratio of 46.89. This indicates respondents with high-risk factor were over 46 times more 257 likely to use drugs (see Table 2 for the details). Attitudes towards drugs also predicted the 258 likelihood of being a drug user with an odds ratio of 4.63, even more so than impulsiveness with 259 an odds ratio of 1.11.

Table 2 should be here

261

262

263

264

265

266

267

268

269

270

271

272

273

274

275

276

277

278

\section{Risk factors contributing to drug users' impulsiveness}

A MANOVA was performed to investigate impact of age groups, gender and drug use as independent variables. Protective factors were not found significant in the analyses above, thus, not included in the MANOVA. In contrast, the risk factors were significant and therefore in order to further disentangle which risk factors contributed to drug users' impulsiveness, we used each domain as independent variables: Family, Community, Friends, and Individual Characteristics. Preliminary assumption testing was conducted to check for normality, linearity, univariate and multivariate outliers, homogeneity of variance-covariance matrices, and multicollinearity, with no serious violations noted. There was a statistically significant difference between drug users and non-users on the combined dependent variables $(F(4,116)=7.14, p=0.0001$; Wilks' Lambda $=$ 0.80; partial eta squared $=0.19)$. When the results for the dependent variables were considered separately, the only difference to reach statistical significance, using a Bonferroni adjusted alpha level of 0.02 , were the risk factor domains of Family $(F(1,119)=8.10, p=0.005$, partial eta squared $=0.06)$, Friends $(\mathrm{F}(1,119)=16.38, p=0.0001$, partial eta squared $=0.12)$, and Individual Characteristics $(\mathrm{F}(1,119)=14.91, p=0.0001$, partial eta squared $=0.11)$. The Family risk factor domain had a significant impact on impulsiveness $(\mathrm{F}(1,119)=5.59, p=0.02$, partial eta squared $=0.05$ ) for the interaction between age group and drug use, see Table 3 for the details. 
In sum, individuals' positive attitude towards drugs is impacted by the total sum of risk

281 factors. Further, the total sum of risk factors, impulsiveness and attitudes towards drugs predicted

282 drug usage. Then again, risk factors dimensions: family, friends and individual's characteristics

283 predicted impulsiveness among drug users.

284

285

286

287

288

289

290

291

292

293

294

295

296

297

298

299

300

301 302 This observation may imply changes in attitudes in a desire to achieve a balance with the social 303 environment (Helkama et al., 2004). In other words, girls might adjust to the "norm" out of fear 304 for exclusion from their peer group (Aronson et al., 2005). At the same time, some researchers

\section{Discussion}

The purpose of this study was to investigate high-school students' attitudes towards drugs, impulsiveness and other risk factors relative to their use of drugs for non-medical reasons in Stockholm, where drugs were known to be a problem (CAN, 2012; NIPH, 2009/10; TNS Sifo, 2012). It was observed that gender and the total sum of risk factor scores predicted positive attitudes toward drug use. The risk factors involve absentee parents, peer-group pressure, hostility towards the child and harsh punishments, poor school or academic achievements, low socioeconomic status as well as the availability of drugs. According to Augustsson (2005), attitudes are part of an existing general social discourse and, currently, young people spend more time outside their family and are more influenced by peers, friends and surroundings than by their own family (Kakihara et al., 2010; Keijsers et al., 2010; Kerr et al., 2010; Stattin \& Kerr, 2000; Vieno et al., 2009). Thus, the development of positive attitudes towards drugs appears to be a combination of risk factors allowing the exposure of the adolescents to a general social discourse. Indeed, teenagers seek out friends with similar interests and attitudes. In this context, social and cultural norms may elucidate gender differences in substance abuse (Kloos et al., 2009). Normally, young males, compared to young females, are often exposed earlier to illicit substances (Van Etten \& Anthony, 2001). In addition, the present study not only revealed that more males 'tried' drugs, but also that more females maintain positive attitudes towards drugs. 
305 suggest that gender differences in drug usage may be explained from an expected gender role

306 perspective - women fear, more so than men, losing control in a social context (Kloos et al., 307 2009).

308 Attitudes towards drugs predicted drug usage. Together with the results suggesting that

309 risk factors lead to positive attitudes towards drugs, our results reveal a 'vicious circle' leading to

310 drug usage, which in turn might lead to further risk factors (e.g., exposure to drug environments).

311 With regard to drug usage, as in most studies, impulsiveness was found also to be a predictor of

312 drug usage. Additionally, friends and family constituted threats that contributed most to a

313 teenager's impulsiveness and drug use propensity, thereby implying individual vulnerability

314 combined with a propensity for antisocial and aggressive behaviour (see Gross, 2007). Indeed,

315 parental guidance combined with support and consequential relationship may prevent drug usage

316 among teenagers (Keijsers et al., 2010; McNeely \& Barber, 2010; Stattin \& kerr, 2000). Parental

317 monitoring and attention facilitates caution in teenagers for choice of peer-association and

318 involvement in risky activities (Vieno et al., 2009). Teenagers' peers constitute risk factors when

319 young people have difficulties in setting limits for themselves and find it difficult to distinguish

320 between right from wrong (Andersson, 1991), that is, teenagers high in impulsiveness.

\section{Limitations of the study}

322 The findings from the current study were based on cross-sectional data; therefore, no

323 causal direction may be specified. For example, do the expressions of impulsiveness imply risky

324 behaviour or some alteration of reward circuits or an epigenetic predisposition? The sample may

325 not be representative of schools across Sweden, or for that matter a region, despite the school

326 being known for drug problems. For instance, 14 out of the total 15 high school principals that

327 were approached about study participation declined to partake due to the nature of the survey.

328 Additionally, self-assessments are subjective measures and may be affected by both personality 
329 traits and dishonest responding (Watson, Clark \& Tellegen, 1988). Although the questionnaire

330 was composed of 127 items, the data offer just a limited portion of information regarding

331 substance use and substance use problems experienced by high-school students in Sweden. Self-

332 reported drug use may have been restricted due to fears of discovery since the survey was

333 completed during an English lecture. Nevertheless, the instruments used here are well-validated

334 and reliable. Finally, the questionnaires were in English, which implies that all the statements

335 retained their original meaning, but it might have distorted the answers. Nevertheless, the

336 principal accepted participation especially because students in this school are well known for

337 their good English.

\section{Future research}

339 An individual's vulnerability for addiction is modulated through several domains

340 including emotional, social, cognitive and a variety of genetic and epigenetic factors (Andershed

341 \& Andershed, 2005; King, 2008; Merline et al., 2004; Nestler, 2012; Schuster et al., 2001).

342 Female high-school students expressed a positive attitude towards the 'normality of drug use'

343 reflecting possibly a liberal outlook (Rytterbro, 2006; Rödner et al., 2007). Future studies should

344 focus on external generalization and long-term trends from samples to different populations.

345 From a cultural perspective, the shared values, norms and ideals expressed about drugs can be

346 understood in terms of the culture that speaks for a social marginalization where drug use in the

347 youth culture described as a normalization trend (Sørensen 2000). This study reinforces the

348 notion that research ought to focus on gender differences relative to pro-drug attitudes along with

349 testing for differences in the predictors of girls' and boys' delinquency and impulsiveness.

\section{Conclusion}

351 An increase in drug use among high-school students was reported with both family and

352 friends as risk factors as well as individual factors, such as impulsiveness. Male students reported 
353 using more drugs, but female pupils expressed more positive pro-drug attitudes. Further, female

354 pupils reported that they had increased their use of drugs compared to earlier findings (TNS Sifo,

355 2012). This observation was hypothesized to constitute a signal for a social change, defined as a

356 change of the norms, values, cultural products and symbols of the society. The pupils' conduct

357 may be interpreted also as an attempt to fit into the "normal" peer group as well as an effort to

358 achieve a balance between individual structures and the social environments. Parental

359 involvement and close relationships promote transparency and reduce the risk that the teenager

360 engages in antisocial behaviour. Importantly, positive attitudes towards drugs among adolescents

361 seem to be part of a 'vicious circle' including risk factors, such as friendly drug environments

362 (e.g., friends who use drugs), unsupportive family environments, individual characteristics, and

363 impulsiveness. All of which contribute to the tendency for drug usage (see Figure 1).

$364 \quad$ Figure 1 should be here

\section{References}

366 Aarnoudse A, Dieleman J, Stricker B. 2007. "Age- and gender-specific incidence of 367 hospitalisation for digoxin intoxication," Drug Safety 30(5), 431-436

368 Andershed, AK, Andershed H. 2005. Norm-breaking behavior in childhood: what does the 369 research say? Stockholm: Gothia

370 Anderson B. 1991. Understanding drug abuse: Practice, situation, process. Lund: Studies in 371 social welfare

372 Anderson P, Baumberg B. 2006. Alcohol in Europe - A public health perspective. A report for the 373 European Commission. London: Institute of Alcohol Studies. 
374 Andersson P, Moller L, Galea G. 2012. Alcohol in the European Union: Consumption, harm and 375 policy approaches. WHO Regional Office for Europe.

376 Aronson E, Wilson TD, Akert RM. 2005. Social psychology. Attitudes and attitude change:

377 Influencing thoughts and feelings. New Jersey: Upper saddle river, 199-235

378 Augustusson G. 2005. The faces of social psychology. Lund: Studentlitteratur

379 Bryan A, Moran R, Farrell E, O’Brien M. 2000. Drug-Related Knowledge, Attitudes and Beliefs

380 in Ireland. Report of a nation-wide survey. Dublin: The Health Research Board

381 Crick N, Grotpeter J. 1995. Relational aggression, gender, and social- psychological adjustment.

382 Child Development Perspectives 66(3): 710-722

383 Deater-Deckard K, Beekman C, Wang Z, Kim J, Petrill S, Thompson L, DeThorne L. 2010. 384 Approach/positive anticipation, frustration/anger, and overt aggression in childhood. $385 \quad$ PeerJ, 78:9911010

386 Duncan SC, Duncan TE, Strycker LA. 2003. Family influences on youth alcohol use: A multiple387 388 sample analysis by ethnicity and gender. Journal of Ethnicity in Substance Abuse 2(2), 17 33

European Monitoring Centre for Drugs and Drug Addiction, Annual Report. 2010. The State of the Drugs Problem in Europe. Publications Office of the European Union, Luxembourg. Commentary: The Current Landscape for European Drug Policy, p. 15. Available at $<\underline{\text { http://www.emcdda.europa.eu.ezp.sub.su.se/attachements.cfm/att 120104_EN_EMCDD }}$

394 European Monitoring Centre for Drugs and Drug Addiction (EMCDDA), Lisbon, November.

395 2010. Annual report on the state of the drugs problem in Europe. Available at 396 http://www.emcdda.europa.eu/publications/annual-report/2010 (Accessed 6 April 2013) 
398 Fraser S, Moore D. 2008. "Dazzled by unity? Order and chaos in public discourse on illicit drug use". Social Science and Medicine 66: 740-752

400 Goldberg T. 1993. Narkotikan avmystifierad. Ett socialt perspektiv. Calrsson Bokförlag. $401 \quad$ Stockholm

402 Gray J. 2007. "Why can't a woman be more like a man?" Clinical Pharmacology and 403 Therapeutics $82(1): 15-17$

404 Gross J. 2007. Handbook of emotion regulation. The Guilford Press, New York

405 Hawkins JD, Catalano RF, Miller JY. 1992. "Risk and protective factors for alcohol and other 406 drug problems in adolescence and early adulthood: implications for substance abuse 407 prevention." Psychological Bulletin 112(1):64-105

408 Helkama K, Myllyniemi R, Liebkind K. 2004. Social psychology : Introduction. Malmö: Liber

409 Henriksson C, Leifman H. 2012. Schoolchildren's drug habit in 2012. Report No. 133, $410 \quad$ Stockholm: Association of Alcohol and Other Drugs (CAN)

411 Hill KG, Hawkins JD, Catalano RF, Abott RD, Guo J. 2005. Family influences on the risk of 412 daily smoking initiation. Journal of Adolescent Health, 37(3): 202-210

413 Jessor R, Turbin MS, Costa FM. 1998b. Risk and protection in successful outcomes among 414 disadvantaged adolescents. Applied Developmental Science, 2: 194-208

415 Johansson K, Wirbing P. 2005. Risk use and abuse: Alcohol - drugs-drugs: awareness and 416 management in primary care, social services and psychiatry. Stockholm: Natur och $417 \quad$ Kultur

418 Johnston LD, O'Malley PM. 2001. Drug Use and Abuse: Psychosocial Aspects. International 419 Encyclopedia of the Social \& Behavioral Sciences, 3861-3866. Ann Arbor, Michigan, $420 \quad$ USA, ISBN: 0-08-043076-7 
421 Kakihara F, Tilton-Weaver L, Kerr M, Stattin H. 2010. The Relationship of Parental Control to

422 Youth Adjustment: Do Youths' Feelings About Their Parents Play a Role? Journal of $423 \quad$ Youth Adolescence 39: 1442-1456

424 Keijsers L, Branje SJT, VanderValk IE, Meeus W. 2010. Reciprocal Effects Between Parental 425 Solicitation, Parental Control, Adolescent Disclosure, and Adolescent Delinquency. $426 \quad$ Journal of Research on Adolescenc 20: 88-113

427 Kerr M, Stattin H, Burk WJ. 2010. A Reinterpretation of Parental Monitoring in Longitudinal 428 Perspective. Journal of Research on Adolescence 20: 39-64

429 King LA. 2008. The science of psychology: An appreciative view. Boston: McGraw- Hill Higher $430 \quad$ Education

431 Kloos A, Weller RA, Chan R, Weller EB. 2009. Gender differences in adolescent substance 432 abuse. Current Psychiatry Reports 11(2)

433 Knight G, Guthrie I, Page M, Fabes R. 2002. Emotional arousal and gender differences in 434 aggression: A meta-analysis. Aggressive Behavior 28(5): 3 66-393

435 Kåver A, Nilsonne Å. 2002. Dialectical Behavior therapy for emotionally unstable personality 436 disorder, theory, strategy, technology. Natur \& Kultur. Stockholm

437 Loeber R, Farrington DP. 1998. Serious and violent juvenile offenders: Risk factors and 438 successful intervention. Thousands Oaks: Sage Publications

439 McNeely CA, Barber BK. 2010. How Do Parents Make Adolescents Feel Loved? Perspectives on $440 \quad$ Supportive Parenting from Adolescents in 12 Cultures. Journal of Adolescent Research 25:

441 601-63Merck Manuals. 2009. For Health care professionals. Accessed 6 April 2013, 442 fromhttp://www.merckmanuals.com/professional/index.html

443 Merline AC, O’Malley PM, Schulenberg JE, Bachman JG, Johnston LD. 2004. Substance use 444 among adults 35 years of age: prevalence, adulthood predictors and impact of adolescent 445 substance use. American Journal of Public Health, 96-102 
446 Moore D. 1994. The lads in action - Social process in an urban youth subculture.

447 Aldershot: Avebury Publishers

448 National Institute of Public Health. 2011. Tobacco - a knowledge base for public health policy 449 report of 2010. Boulder: National Institute of Public Health 2

450 National Institute of Public Health. 2010. Drug use in Sweden, Report No. 13

451 Available at http://www.fhi.se/PageFiles/10810/R2010-13-Narkotikabruket-i-Sverige.pdf

$452 \quad$ (Accessed 10 February 2013)

453 Nestler EJ. 2012. Transcriptional mechanisms of drug addiction. Clin Psychopharmacol $454 \quad$ Neurosci. 10(3):136-43. doi: 10.9758/cpn.2012.10.3.136.

455 Pallant J. 2001. SPSS survival manual. Maidenhead, Philadelphia: Open University Press

456 Patton JH, Stanford MS, Barratt ES. 1995. Factor structure of the Barratt Impulsiveness Scale.

457 Journal of Clinical Psychology 51(6): 768-774

458 Pires P, Jenkins JM. 2007. A growth curve analysis of the joint influences on parenting affect, 459 child characteristics and deviant peers on adolescent illicit drug use. Journal of Youth and $460 \quad$ Adolescence, 36: 169-183

461 Ramström J. 1983. Narkomani. Orsaker och behandling. Tiden/Folksam. Stockholm

462 Rytterbro LL. 2006. Young people's attitudes to drugs "In SNIPH What is it that makes young 463 drug testing and what makes some stick? Report No. 15

464 Rödner, Hansson S, Olsson M. 2007. Socially integrated drug users, myth or reality? A study of 465 socially integrated young adult drug use in the Stockholm area. Stockholm University, $466 \quad$ Research Report No. 47

467 Sale E, Sambrano S, Springer JF, Pena C, Pan W, Kasim R. 2005. Family protection and 468 prevention of alcohol use among Hispanic youth at high risk. American Journal of 469 Community Psychology, 36(3/4): 195-205 
Sifo.

2012.

Available http://norrareal.stockholm.se/sites/default/files/gymnundersokning_2012_stkholm.pdf (accessed 10 February 2013).

Schuster C, O’Malley PM, Bachman JG, Johnston LD, Schulenberg J. 2001. Adolescent marijuana use and adult occupational attainment: a longitudinal study from age 18 to 28 Subst. Use Misuse, 36: 997-1014

Sulkunen P, Alasuutari P, Nätkin R, Kinnunen M. 1997. The Urban Pub. Helsinki: Stakes.

Sørensen A. 2000. Social and (sub) cultural construction of substance use. Nordisk alkoholoch narkotikatidskrift (NAT), vol. 17, English supplement.

Stattin H, Kerr M. 2000. Parental Monitoring: A reinterpretation. Child Development, 71:10721085

481 The Free Dictionary, Medical Dictionary. 2013. Available athttp://medical482 dictionary.thefreedictionary.com/abuse, 2013 (accessed 12 April)

483 Trulsson K. 2006. [Tightrope: on women abuse, and family therapy]. Stockholm: Carlsson $484 \quad$ Bokförlag

485 United Nations Office on Drugs and Crime (UNODC). 2011. World Drug Report, United 486 Nations, New York, ISBN: 978-92-1-148262-1. Available at $487 \quad$ http://www.unodc.org/documents/data-and analysis/WDR2011/World_Drug_Report_2011_ebook.pdf (accessed 2 April 2013)

Van Etten ML, Anthony JC. 2001. Male-female differences in transitions from first drug opportunity to first use: searching for subgroup variation by age, race, region, and urban

492 Vieno A, Nation M, Pastore M, Santinello M. 2009. Parenting and antisocial behaviour: A model 493 of the relationship between adolescent self-disclosure, parental closeness, parental control 494 and adolescent antisocial behaviour. Developmental Psychology, 45: 1509-1519 
495 Watson D, Clark LA, Tellegen A. 1988. Development and validation of brief of positive and 496 negative affect: the PANAS scale. Journal of Personality and Social Psychology, 564:

$497 \quad 1063-1070$ 


\section{Table 1 (on next page)}

Logistic regression analysis predicting respondents' attitude towards drugs. 
Table 1. Logistic regression analysis predicting respondents' attitude towards drugs.

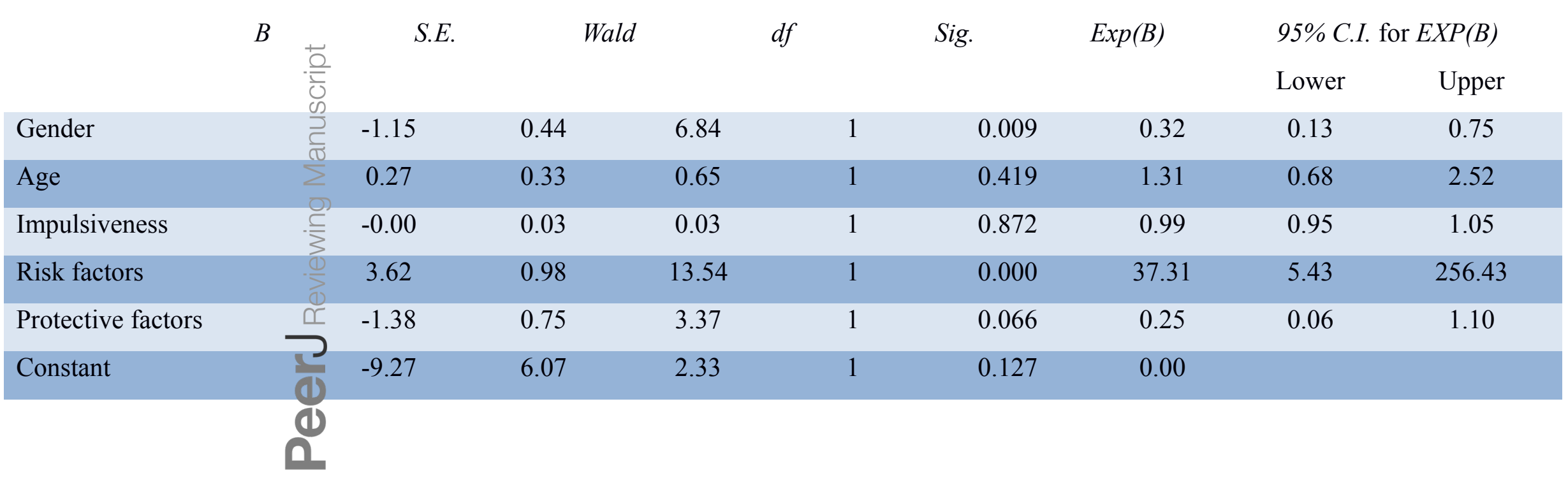




\section{Table 2 (on next page)}

Logistic regression analysis for likelihood that that the respondents would report that they had used drugs. 
Table 2. Logistic regression analysis for likelihood that that the respondents would report that they had used drugs.

\begin{tabular}{|c|c|c|c|c|c|c|c|c|c|}
\hline \multirow[t]{2}{*}{ Variable } & \multirow[b]{2}{*}{ 을 } & \multirow[t]{2}{*}{$B$} & \multirow[t]{2}{*}{ S.E. } & \multirow[t]{2}{*}{ Wald } & \multirow[t]{2}{*}{$d f$} & \multirow[t]{2}{*}{ Sig. } & \multirow[t]{2}{*}{$\operatorname{Exp}(B)$} & \multicolumn{2}{|c|}{$95 \%$ C.I. for $E X P(B)$} \\
\hline & & & & & & & & Lower & Upper \\
\hline Gender & $\overline{0}$ & -0.38 & 0.55 & 0.47 & 1 & 0.495 & 0.69 & 0.23 & 2.03 \\
\hline Age & & -0.21 & 0.41 & 0.27 & 1 & 0.604 & 0.81 & 0.37 & 1.79 \\
\hline Protective factors & ర) & -1.63 & 0.95 & 2.95 & 1 & 0.086 & 0.20 & 0.03 & 1.26 \\
\hline Impulsiveness & $\cdot \frac{c}{3}$ & 0.11 & 0.03 & 10.08 & 1 & 0.002 & 1.11 & 1.04 & 1.19 \\
\hline Atittudes towards drugs & & 1.53 & 0.55 & 7.68 & 1 & 0.006 & 4.63 & 1.57 & 13.68 \\
\hline
\end{tabular}




\section{Table 3 (on next page)}

Family, community, friends and individual characteristics as risk factors for drug user's impulsiveness as indicated by the MANOVA 
Table 3. Family, community, friends and individual characteristics as risk factors for drug user's impulsiveness as indicated by the MANOVA

\begin{tabular}{|c|c|c|c|c|c|c|c|}
\hline Source & $\begin{array}{l}\text { Tests of Between-Subjects Effects } \\
\text { Dependent Variable } \\
\end{array}$ & $\begin{array}{l}\text { Type III } \\
\text { Sum of } \\
\text { Squares }\end{array}$ & $d f$ & $\begin{array}{l}\text { Mean } \\
\text { Square }\end{array}$ & $F$ & Sig. & $\begin{array}{l}\text { Partial } \\
\text { Eta } \\
\text { Squared } \\
\end{array}$ \\
\hline \multirow{3}{*}{ Age groups } & Family & 311.22 & 1 & 311.22 & 3.27 & 0.073 & 0.03 \\
\hline & Friends $\sum$ & 0.00 & 1 & 0.002 & 0.00 & 0.965 & 0.00 \\
\hline & Individual Characteristics & 4.40 & 1 & 4.40 & 0.89 & 0.348 & 0.01 \\
\hline \multirow{2}{*}{ Drug use } & Family & 771.42 & 1 & 771.42 & 8.10 & 0.005 & 0.06 \\
\hline & Community & 18.48 & 1 & 18.48 & 1.18 & 0.279 & 0.01 \\
\hline \multirow{4}{*}{$\begin{array}{l}\text { Age groups * } \\
\text { Drug use }\end{array}$} & Family & 532.93 & 1 & 532.93 & 5.59 & 0.020 & 0.05 \\
\hline & Commun & 8.81 & 1 & 8.81 & 0.56 & 0.454 & 0.01 \\
\hline & Friends & 0.15 & 1 & 0.15 & 0.15 & 0.700 & 0.00 \\
\hline & Individu Characteristics & 3.00 & 1 & 3.00 & 0.61 & 0.438 & 0.01 \\
\hline
\end{tabular}




\section{Figure 1}

A vicious circle including positive attitude towards drugs, risk factors and, impulsiveness. All increasing the risk of using drugs.

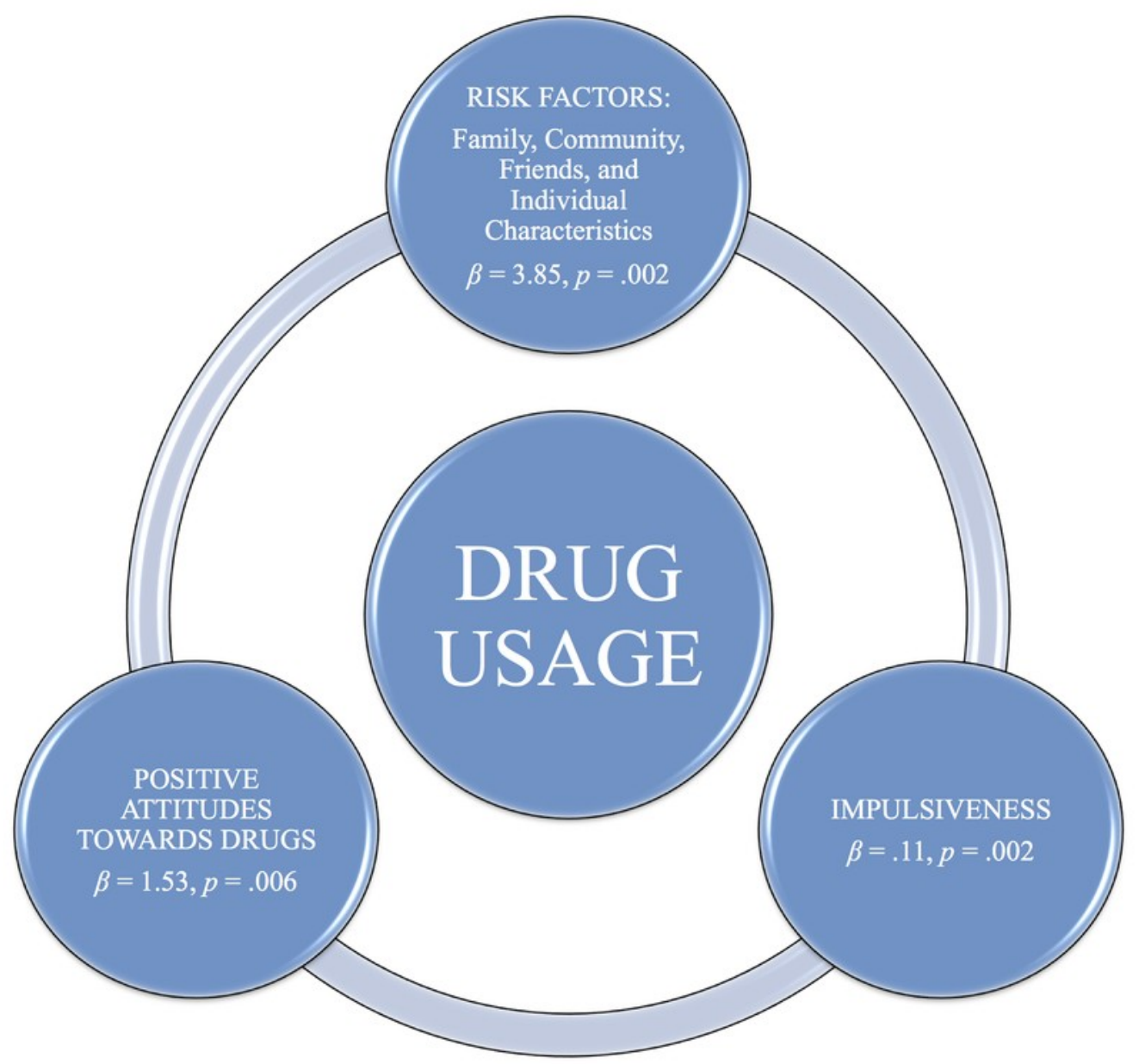

